\title{
Analysis of Subcutaneous Anterior Transposition versus in-situ Decompression of UInar Nerve with Force Transducer in Cadaver Specimen
}

\author{
Bekir Eray KILINC ${ }^{1}$, Haluk CELIK², Yunus $\mathrm{OC}^{3}$, Ruhat UNLU ${ }^{1}$, Elif Nedret KESKINOZ ${ }^{4}$, Baris YILMAZ \\ ${ }^{1}$ Health Science University Fatih Sultan Mehmet Training and Research Hospital, Department of Orthopaedics and Traumatology, \\ Istanbul, Turkey \\ ${ }^{2}$ Health Science University Umraniye Training and Research Hospital, Department of Orthopaedics and Traumatology, Istanbul, Turkey \\ ${ }^{3}$ Bagcilar Medilife Hospital, Department of Orthopaedics and Traumatology, Istanbul, Turkey \\ ${ }^{4}$ Acibadem Mehmet Ali Aydinlar University, School of Medicine, Department of Anatomy, Istanbul, Turkey
}

Corresponding author: Bekır Eray KILINC dreraykilinc@gmail.com

\section{ABSTRACT}

AIM: To evaluate the changes in the pressure values of the ulnar nerve after in-situ decompression and anterior subcutaneous transposition of the ulnar nerve.

MATERIAL and METHODS: The ulnar nerve was released in the postcondylar groove. An ultrathin (100 Im) force transducer was embedded between the posterior of the ulnar nerve and the anterior of the medial epicondyle. The elbow joint was flexed from full extension position to maximum flexion and was measured to obtain the maximum stress at $0^{\circ}, 45^{\circ}, 90^{\circ}$, and $135^{\circ}$ of flexion. Then, the ulnar nerve was transposed anterior subcutaneously. The same measurement was applied to the two procedures. Data were compared between the two surgical techniques.

RESULTS: Our study was performed on the right upper extremities of eight (seven men and one woman) fresh frozen cadavers. The mean age of the cadavers was $67.25 \pm 12.2$ years. Mean values of $0^{\circ}, 45^{\circ}, 90^{\circ}$, and $135^{\circ}$ of flexion after the ulnar nerve insitu decompression were $0.41,0.9,1.7$, and $4.3 \mathrm{~N}$, respectively. Mean values of $0^{\circ}, 45^{\circ}, 90^{\circ}$, and $135^{\circ}$ of flexion after anterior transposition of the ulnar nerve were $0.3,0.73,1.63$, and $2.15 \mathrm{~N}$, respectively. No significant difference was noted between the two groups in terms of $0^{\circ}, 45^{\circ}$, and $90^{\circ}$ of flexion values. However, there was a significant difference between the two groups in the $135^{\circ}$ of flexion measurement values.

CONCLUSION: Anterior transposition is a more appropriate technique than in-situ decompression in the treatment of cubital tunnel syndrome that does not respond to conservative treatment regardless of the severity of the symptom.

KEYWORDS: Entrapment neuropathy, Ulnar nerve, In-situ decompression, Anterior transposition, Flexiforce

\section{INTRODUCTION}

U Inar entrapment neuropathy is the second most common nerve entrapment in the upper extremity. The ulnar nerve may be compressed at several levels along its course in the upper extremity, but the elbow is the most common region of entrapment $(7,8,24)$. Cubital tunnel syndrome (CUTS) refers to the compression of the ulnar nerve at the elbow.

Although the incidence is higher in men than in women, it is $25 / 100,000$ per year $(1,19)$. Numerous factors such as trauma, compression, bone spur and muscle disorders, ulnar nerve dislocation from the medial epicondyle, and ganglion and
Bekir Eray KILINC (1) : 0000-0003-1229-9815

Haluk CELIK (1) : 0000-0003-4798-1400

Yunus OC (1D:0000-0001-9023-7375
Ruhat UNLU (1): 0000-0001-9183-0250

Elif Nedret KESKINOZ (D) : 0000-0002-3298-6842

Baris YILMAZ (1) : 0000-0003-2277-0949 
congenital anomalies may cause ulnar nerve entrapment. CUTS clinically manifests itself as pain, numbness, motor strength loss, and muscle atrophy on the ulnar side of the forearm and in the fourth and fifth digits. In untreated cases, pain and clumsiness along with loss of sensation and strength may arise on the affected side. Although conservative treatments such as night splint and activity modification may be effective in patients with mild compression findings $(13,25,27,28,30)$, surgical treatment is administered in cases of persistent paresthesia, muscle weakness, or pain unresponsive to conservative treatment.

Several surgical procedures have been described for the treatment of CuTS. Today, it is still not possible to speak of the best treatment $(9-11,13,25,31)$. Many techniques such as isolated decompression, anterior transposition with decompression, medial epicondylectomy, and arthroscopic decompression have been described. No consensus has been established on the surgical technique selection.

Given the literature, there are no data regarding the measurement of pressure arising on the nerve after surgical treatments for CuTS. In our cadaver study, we aimed to evaluate the changes in the values of pressure arising on the ulnar nerve after in-situ decompression and anterior subcutaneous transposition of the ulnar nerve in the cadaveric specimens.

\section{MATERIAL and METHODS}

This experimental study was conducted on the upper extremities of eight fresh frozen cadavers, at Acibadem Mehmet Ali Aydinlar University on April 2019. Approval for our study was obtained from the Institutional Review Board (Approval No: 2019-10/4; 23.05.2019). The demographic changes of the cadavers were recorded. Cadavers that had a deformity, contracture in the elbow region, or had previously undergone elbow dissection were excluded from the study. Ulnar nerve dissection was carried out by the researchers. Dissection was performed on eight cadaveric elbows using the medial approach. A 10-cm longitudinal incision was made at the posterior of the medial humeral condyle through the retrocondylar groove. The ulnar nerve was exposed in the postcondylar groove and advanced to the flexor carpi ulnaris Osborne's ligament at the distal part and from the medial epicondyle to the intermuscular septum at the proximal part.

Briefly, an ultrathin $(100 \mathrm{~lm})$ force transducer was embedded between the posterior of the ulnar nerve and the anterior of the medial epicondyle (Figure 1). The contact stress on the ulnar nerve was calculated by dividing the total force on the sensor by the sensing area. The elbow joint was flexed from full extension position to maximum flexion and was measured to obtain the maximum stress at $0^{\circ}, 45^{\circ}, 90^{\circ}$, and $135^{\circ}$ of flexion. The force exerted on the ulnar nerve was measured by a flexiforce pressure sensor (Nitta Co., Ltd., Osaka, Japan). The details of the measurement system have previously been reported in the literature (2).

Then, the ulnar nerve was freed from its retroepicondylar tunnel and transposed forward subcutaneously. Force transducer placement was completed for pressure value measurements.
A subcutaneous flap is created at the elbow to accommodate the transposed ulnar nerve. The same measurement was applied to the two procedures. Data were compared between the two surgical techniques.

Statistical analysis was performed using SPSS version 12 (SPSS Inc, Chicago, IL, USA). Means and standard deviations were calculated to summarize the study data. Normal distribution was investigated using the Shapiro-Wilk test. Continuous variables were compared using the Mann-Whitney $U$ test. The threshold for significance was set at $p<0.05$.

\section{RESULTS}

A total of eight cadaveric specimens, four men and four women, were included in the study. Of the cadavers, eight were right upper extremity. All cadavers had a full range of motion of the elbow joint. The mean age of the cadavers was $67.25 \pm 12.2$ years (51-88). Mean values of $0^{\circ}, 45^{\circ}, 90^{\circ}$, and $135^{\circ}$ of flexion after ulnar nerve in-situ decompression were $0.41,0.9,1.7$, and $4.3 \mathrm{~N}$, respectively. Mean values of $0^{\circ}, 45^{\circ}$, $90^{\circ}$, and $135^{\circ}$ of flexion after anterior transposition of the ulnar nerve were $0.3,0.73,1.63$, and $2.15 \mathrm{~N}$, respectively (Table I). In the statistical analysis, there was no difference between the two groups in terms of the pressure values at $0^{\circ}, 45^{\circ}$, and $90^{\circ}$ of flexion (Figures 2-4). But when the values measured at $135^{\circ}$ of elbow flexion were compared, we found that the values of the patients who underwent ulnar nerve in-situ decompression were higher, which was statistically significant $(p<0.001$; Table I and Figure 5).

\section{DISCUSSION}

Anterior transposition of the ulnar nerve is performed as the primary surgical procedure in CuTS. Transposition performed in this technique provides direct decompression of the nerve and prevents the traction of the nerve at elbow flexion $(17,18,25)$.

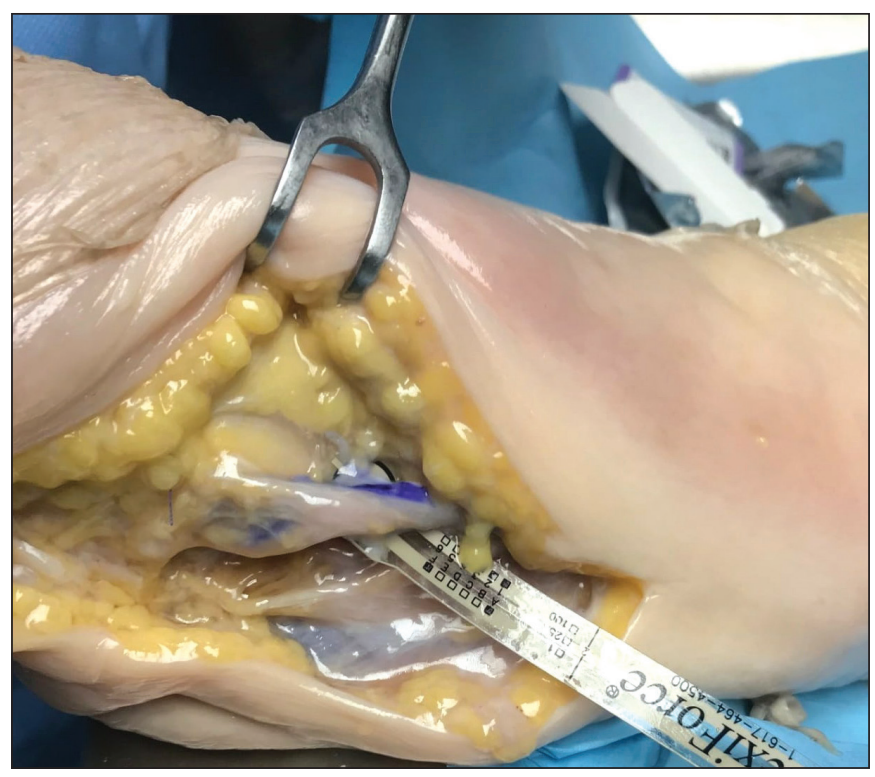

Figure 1: Transducer application after in-situ decompression. 
The incidence of CUTS has increased in some occupational groups with work that requires leaning on the elbow, gripping a hand tool, and performing repetitive elbow flexion and extension. The best treatment method for CuTS is controversial. Given the literature, no superiority of anterior transposition over other surgical modalities, such as simple decompression, has been demonstrated (4,5,19-22). Erbayraktar et al. have shown that there is no significant difference in the therapeutic outcomes between in-situ decompression of the ulnar nerve and anterior transposition of the ulnar nerve in the treatment of ulnar neuropathy, regardless of the severity of neuropathy (8). However, most authors have emphasized that simple

Table I: Descriptives of Two Groups ( $n=8)$

\begin{tabular}{|c|c|c|c|c|c|}
\hline & \multicolumn{2}{|c|}{ In-situ decompression } & \multicolumn{2}{|c|}{ Anterior transposition } & \multirow[b]{2}{*}{$\mathbf{p}^{*}$} \\
\hline & Mean & SD & Mean & SD & \\
\hline $0^{\circ}$ & 0.41 & .18 & 0.3 & 0.14 & 0.21 \\
\hline $45^{\circ}$ & 0.9 & 0.22 & 0.73 & 0.19 & 0.15 \\
\hline $90^{\circ}$ & 1.7 & 0.2 & 1.63 & 0.15 & 0.16 \\
\hline $135^{\circ}$ & 4.3 & 0.7 & 2.15 & 0.29 & 0.001 \\
\hline
\end{tabular}

*Mann-Whitney U test.

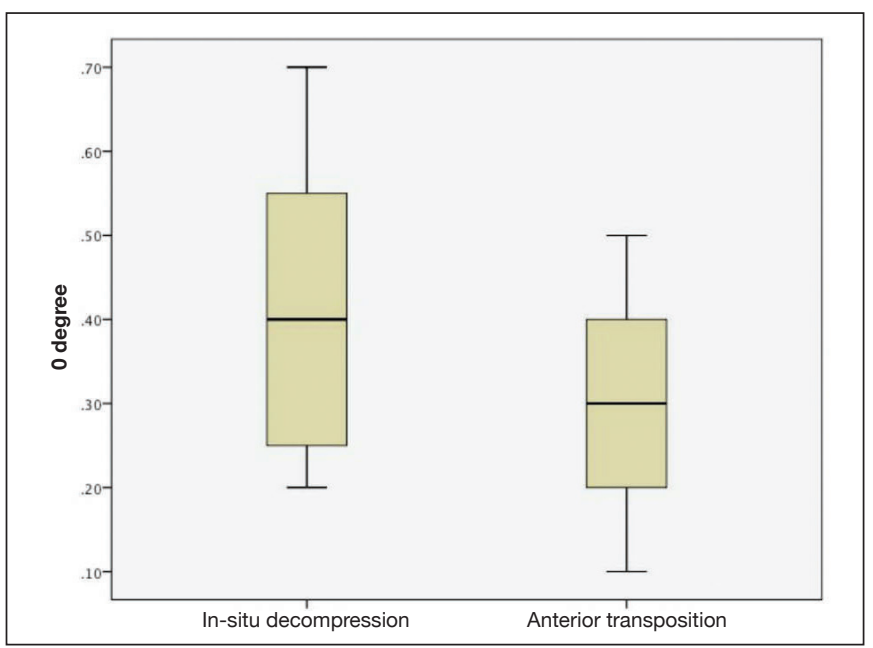

Figure 2: $0^{\circ}$ of flexion comparison.

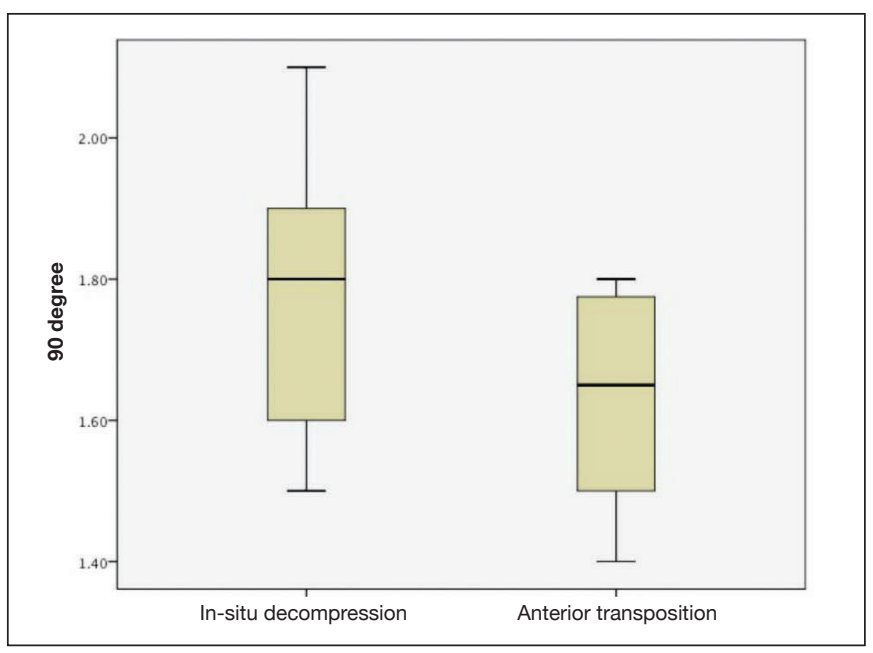

Figure 4: $90^{\circ}$ of flexion comparison.

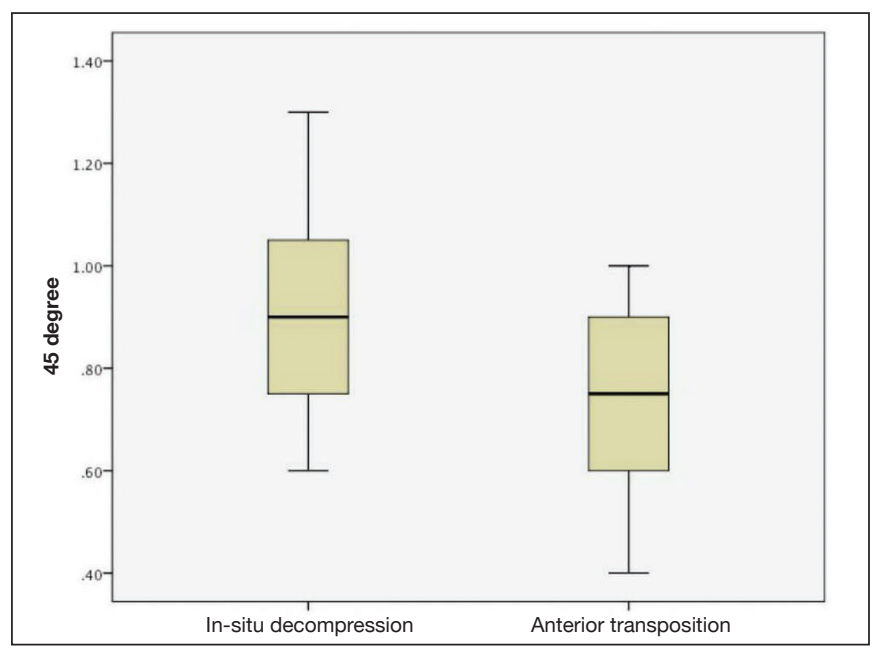

Figure 3: $45^{\circ}$ of flexion comparison.

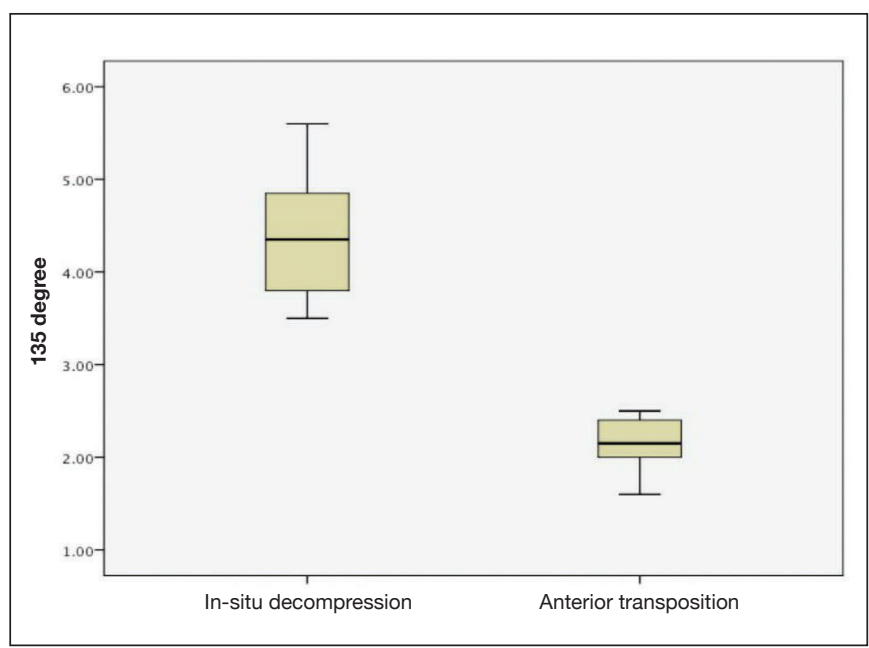

Figure 5: $135^{\circ}$ of flexion comparison. 


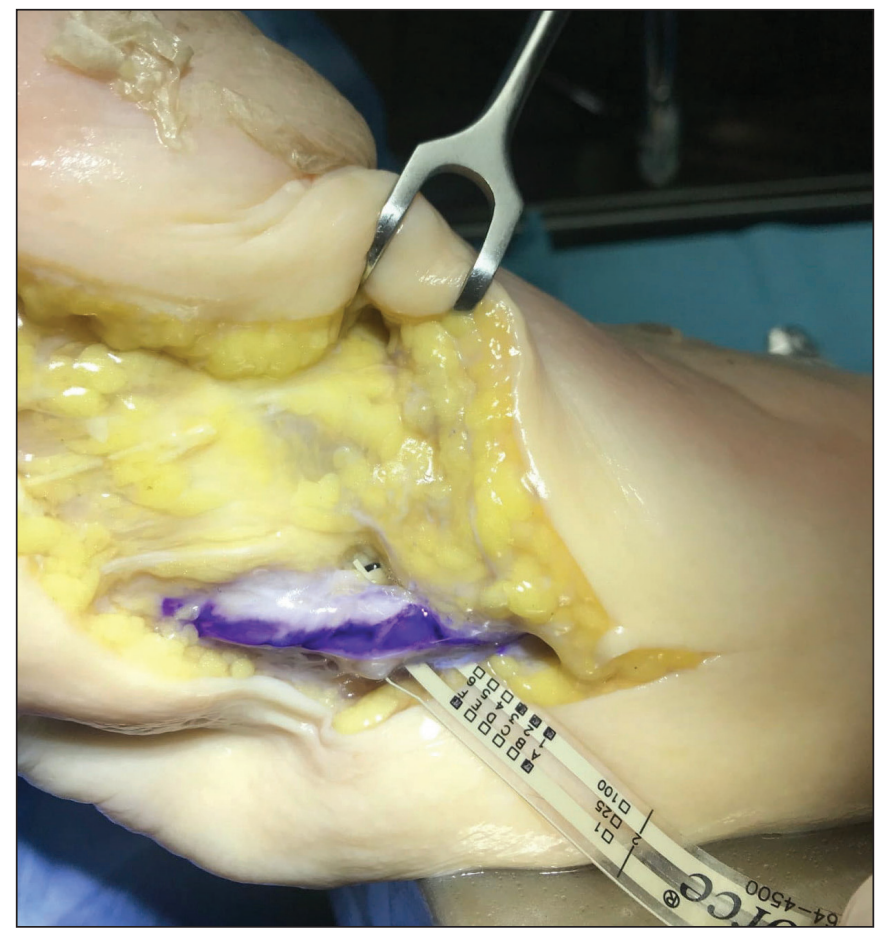

Figure 6: Transducer application after transposition.

decompression is not a good option in the treatment of CuTS $(11,15,21)$. In our study, we found that the cadaveric ulnar nerve that underwent simple decompression was exposed to a higher pressure than the anteriorly transposed ulnar nerve at $135^{\circ}$ of elbow flexion. We think that the traction-related pressure effect induced by elbow flexion on the ulnar nerve that underwent anterior transposition is lower. Although no superiority was asserted between the two techniques in the literature, the results of our study demonstrated that anterior transposition was a more effective method because of reduced pressure on the ulnar nerve.

Medial epicondylectomy is another method described in CuTS. However, complications such as tenderness, postoperative pain, flexor-pronator weakness, and valgus instability have been reported to develop after medial epicondylectomy $(11,21)$. Although it has advantages over anterior transposition, the fact that it is a technique that most surgeons are unfamiliar with and has some weaknesses are its disadvantages. However, it is not an appropriate technique in an elbow with excessive valgus and ulnar nerve subluxation.

Ulnar nerve instability is the most important factor in failed cubital tunnel decompression with a rate of $2.4 \%-20 \%$. Ulnar nerve instability that may arise following simple decompression should be paid attention. In a cadaver study, the rate of instability is $50 \%$, especially in decompression carried out more than $4 \mathrm{~cm}$ proximally to the medial epicondyle (6).

Dellon et al. indicated that anterior transposition is the best method to reduce the pressure arising on the nerve (6). Some authors have reported that anterior transposition leads to devascularization of the nerve (17). However, King and Morgan demonstrated the presence of perineural anastomoses after anterior transposition (17). Moreover, Prevel et al., and Sugawara refused devascularization by stating that transposition transports not only the ulnar nerve but also its collateral vessels $(23,29)$. To prevent this complication, its location in the epicondylar groove should be preserved during decompression, and it should not be dissected circularly to preserve the feeding vessels and surrounding soft tissues.

To maintain the stabilization of the ulnar nerve, compressive superficial bands should be released without applying neurolysis. Elbow movements should be checked for subluxation after the release, and anterior transposition should be performed in cases where subluxation is observed $(14,16)$. Anterior transposition of the ulnar nerve is especially preferred in patients who previously had elbow trauma, had elbow arthropathy with concomitant contracture, and underwent ulnar neuropathy surgery. Many surgeons recommend transposition in patients with high-grade McGowan lesion, preoperative ulnar nerve subluxation, and developed ulnar nerve instability during in-situ decompression. In the study by Hsu et al., it was found that the rate of subluxation was much higher in the release of the anterior connection of Osborne's ligament on the medial epicondyle than that of in the release of the posterior connection in the olecranon (16). Uscetin et al. reported that the epitrochleoanconeus muscle should be kept in mind as a rare cause of CUTS (31). They reported that subfascial anterior transposition might be accepted as a good surgical alternative to prevent subluxation after complete dissection of the ulnar nerve.

The quantitative measurement values used are the strengths of our study. We demonstrated that anterior transposition reduces the pressure that the ulnar nerve is exposed in elbow flexion more than in-situ decompression in the treatment of CUTS. We would like to emphasize that anterior transposition is the best treatment in CUTS since we detected ulnar nerve instability that may develop after decompression, recurrence due to inadequate decompression, and inadequate decompression at full elbow flexion.

In recent years, endoscopic ulnar nerve decompression has been gaining popularity with the advantages of a small incision, low rate of ulnar nerve injury, and rapid recovery time (12). However, it has not been widely adopted because of the requirement for more expensive instruments, the duration of the learning curve, and the complication rates compared with open decompression techniques $(3,18)$.

\section{CONCLUSION}

The treatment of CuTS has not yet been standardized. With our study, we believe that the choice of anterior transposition in the treatment of CuTS syndrome will relax the nerve more than in-situ decompression treatment, reduce the tractionrelated compression arising in elbow flexion, relieve the patient's complaints more, and decrease the recurrence rates. Anterior transposition is an appropriate technique to be used in the treatment of CUTS unresponsive to conservative treatment regardless of the symptom severity. 


\section{REFERENCES}

1. Apfelberg DB, Larson SJ: Dynamic anatomy of the ulnar nerve at the elbow. Plast Reconstr Surg 51(1):79-81, 1973

2. Bartels $\mathrm{RH}$, Termeer $\mathrm{EH}$, van der Wilt GJ, van Rossum LG, Meulstee J, Verhagen WI, Grotenhuis JA: Simple decompression or anterior subcutaneous transposition for ulnar neuropathy at the elbow: A cost-minimization analysis: Part 2. Neurosurgery 56(3):531-536, 2005

3. Bartels $\mathrm{RH}$, Verhagen $\mathrm{WI}$, van der Wilt GJ, Meulstee J, van Rossum LG, Grotenhuis JA: Prospective randomized controlled study comparing simple decompression versus anterior subcutaneous transposition for idiopathic neuropathy of the ulnar nerve at the elbow: Part 1. Neurosurgery 56:522530,2005

4. Calisaneller T, Ozdemir O, Caner H, Altinors N: Simple decompression of the ulnar nerve at the elbow via proximal and distal mini skin incisions. Turk Neurosurg 21(2):167-171, 2011

5. Davies MA, Vonau M, Blum PW, Kwok BC, Matheson JM, Stening WA: Results of ulnar neuropathy at the elbow treated by decompression or anterior transposition. Aust N Z J Surg 61:929-934, 1991

6. Dellon AL, Chang E, Coert JH, Campbell KR: Intraneural ulnar nerve pressure changes related to operative techniques. J Hand Surg Am 19:923-930, 1994

7. Eliaspour D, Sedighipour L, Hedayati-Moghaddam MR, Rayegani SM, Bahrami MH, Roghani RS: The pattern of muscle involvement in ulnar neuropathy at the elbow. Neurol India 60:36-39, 2012

8. Erbayraktar S, Sade B, Tekinsoy B: Comparison of simple decompression and superficial transposition in patients with advanced cubital tunnel syndrome. Turk Neurosurg 11:51-55, 2001

9. Fernandes $\mathrm{CH}$, Matsumoto $\mathrm{MH}$, Honmoto PK, Lima MF, Faloppa F, Albertoni WM, Carneiro RO: Transposição anterior submuscular do nervo ulnar para o tratamento da síndrome do túnel cubital. Rev Bras Ortop 33(6):465-471, 1998

10. Foran I, Vaz K, Sikora-Klak J, Ward SR, Hentzen ER, Shah SB: Regional ulnar nerve strain following decompression and anterior subcutaneous transposition in patients with cubital tunnel syndrome. J Hand Surg Am 41(10):e343-e350, 2016

11. Gelberman RH, Yamaguchi K, Hollstien SB, Winn SS, Heidenreich FP Jr, Bindra RR, Hsieh P, Silva MJ: Changes in interstitial pressure and cross-sectional area of the cubital tunnel and of the ulnar nerve with flexion of the elbow. An experimental study in human cadavera. J Bone Joint Surg Am 80:492-501, 1998

12. Glowacki KA, Weiss AP: Anterior intramuscular transposition of the ulnar nerve for cubital tunnel syndrome. J Shoulder Elbow Surg 6:89-96, 1997

13. Goldfarb CA, Sutter MM, Martens EJ, Manske PR: Incidence of re-operation and subjective outcome following in situ decompression of the ulnar nerve at the cubital tunnel. J Hand Surg Eur Vol 34:379-383, 2009

14. Heithoff ST: Cubital tunnel syndrome does not require transposition of the ulnar nerve. J Hand Surg Am 24:898-905, 1999
15. Hurvitz AP, Fitzgerald BT, Kroonen LT: Wide decompression may render the ulnar nerve unstable: A cadaveric study. J Surg Orthop Adv 25:176-179, 2016

16. Hsu PA, Hsu AR, Sutter EG, Levitz SP, Rose DM, Segalman $K A$, Lee SK: Effect of anterior versus posterior in situ decompression on ulnar nerve subluxation. Am J Orthop (Belle Mead NJ) 42:262-266, 2013

17. King T, Morgan FP: Late results of removing the medial humeral epicondyle for traumatic ulnar neuritis. J Bone Joint Surg $\mathrm{Br}$ 41:51-55, 1959

18. Manske PR, Johnston R, Pruitt DL, Strecker WB: Ulnar nerve decompression at the cubital tunnel. Clin Orthop 274:231237, 1992

19. Mondelli M, Giannini F, Ballerini M, Ginanneschi F, Martorelli E: Incidence of ulnar neuropathy at the elbow in the province of Siena (Italy). J Neurol Sci 234(1-2):5-10, 2005

20. Nabhan A, Ahlhelm F, Kelm J, Reith W, Schwerdtfeger K, Steudel WI: Simple decompression or subcutaneous anterior transposition of the ulnar nerve for cubital tunnel syndrome. J Hand Surg Br 30:521-524, 2005

21. Nathan PA, Istvan JA, Meadows KD: Intermediate and longterm outcomes following simple decompression of the ulnar nerve at the elbow. Chir Main 24:29-34, 2005

22. Nellans K, Tang P: Evaluation and treatment of failed ulnar nerve release at the elbow. Orthop Clin North Am 43:487-494, 2012

23. Prevel CD, Matloub HS, Ye Z, Sanger JR, Yousif NJ: The extrinsic blood supply of the ulnar nerve at the elbow: An anatomic study. J Hand Surg Am 18:433-438, 1993

24. Robertson C, Saratsiotis J: A review of compressive ulnar neuropathy at the elbow. J Manipulative Physiol Ther 28(5):345, 2005

25. Shah CM, Calfee RP, Gelberman RH, Goldfarb CA: Outcomes of rigid night splinting and activity modification in the treatment of cubital tunnel syndrome. J Hand Surg Am 38:1125-1130, 2013

26. Simsek S, Er U, Demirci A, Sorar M: Operative illustrations of the Osborne's ligament. Turk Neurosurg 21(2):269,270, 2011

27. Song JW, Waljee JF, Burns PB, Chung KC, Gaston RG, Haase SC, Hammert WC, Lawton JN, Merrell GA, Nassab PF, Yang LJ: An outcome study for ulnar neuropathy at the elbow: $A$ multicenter study by the Surgery for Ulnar Nerve (SUN) study group. Neurosurgery 72:971-982, 2013

28. Staples R, London DA,Dardas AZ, Goldfarb CA, Calfee RP: Comparative morbidity of cubital tunnel surgeries: A prospective cohort study. J Hand Surg Am 43:207-213, 2018

29. Sugawara M: Experimental and clinical studies of the vascularized anterior transposition of the ulnar nerve for cubital tunnel syndrome. Nippon Seikeigeka Gakkai Zasshi 62:755-766, 1988

30. Suzuki T, Iwamoto T, Ochi K, Mito K, Nakamura T, Suzuki $\mathrm{K}$, Yamada H, Sato K: Cigarette smoking is associated with cubital tunnel syndrome. Muscle Nerve 54:1136-1138, 2016

31. Uscetin I, Bingol D, Ozkaya O, Orman C, Akan M: Ulnar nerve compression at the elbow caused by the epitrochleoanconeus muscle: A case report and surgical approach. Turk Neurosurg 24(2):266-271, 2014 